phate $\left(\mathrm{P}_{2} \mathrm{O}_{5}\right)$ or $10 \mathrm{mgm}$. nitrate nitrogen per cubic metre) usually extended down to $150-200$ metres, and in this connexion red algæ have been found growing in this sea down to 130 metres, far below the limit to which sufficient light could penetrate in the more turbid northern waters. $\dagger$ Thus it would seem that the very scarcity of nourishment and resulting sparseness of sub-surface life enables light to penetrate far into the water for plants there to utilise the minute quantities of phosphate and nitrate which diffuse up from the meagre bottom store. Perhaps, indeed, in the Mediterranean the region most favourable for planktonic organisms may be far removed from the surface, at, say, 100 metres, where a sufficiency both of light and of nutrient salts are found together. This is far lower than is found anywhere in waters around Great Britain. Experimental data on the amount and quality of the light penetrating to such depths and of its suitability for photosynthesis should prove illuminating.

† Harvey, H. W., " Biological Chemistry and Plyysics of Sea Water". Cambritge, 1928.
The concentrations of both phosphate and nitrate decrease going eastward from the Straits of Gibraltar. In the Egean Sea phosphates were not detected at any depth, and nitrates were very poor. It is manifest that life cannot flourish on any considerable scale in such impoverished waters. In the Straits of Messina nitrate appeared to be comparatively high, apparently due to vertical mixing, but it was unaccompanied by phosphate and was presumably therefore of little value.

The scarcity of nutrient salts in the Mediterranean is attributed by Thomsen to the exchange of water through the Straits of Gibraltar, since Atlantic surface water, already poor in nitrate and phosphate, runs in over the outgoing bottom current of Mediterranean water. This exchange of water has been well established by several vessels, including the Dana, and Thomsen's own analyses in the Straits and the Alboran Sea testify to the impoverishment of the inflowing Atlantic surface water, at any rate in April and June.

L. H. N. C.

\title{
Acoustic and Telephone Measurements
}

$\mathrm{N}$ a paper read by $\mathrm{H}$. R. Harbottle to the Institution of Electrical Engineers on April 8, a brief description is given of some of the work carried out in the research section of the British Post Office. He begins by discussing electro-acoustic and acousto-electric measurements of instruments. $\mathrm{He}$ next describes voice-ear measurements on microphones and receivers, and finally deals with mechanical tests by means of which rapid acceptance tests can be made and estimates given of the commercial life of instruments.

Mr. Harbottle attributes the progress made during recent years to the methods invented of expressing the results of measurements in telephony by reference to absolute units. These methods followed on the invention and development of the thermionic valve. This has enabled acoustic pressures and velocities to be measured accurately, and has led to the rapid advances made in radio-telephony. This in turn has promoted world-wide telephonic communication.

To enable this to be done, an international com mittee had to be formed, called the C.C.I.-Comité Consultatif International des Communications Téléphoniques à grande distance-the objects of which were the formulation of correct methods of measurement. Standard instruments were required which had to give a constant response over the range at which they were used. At the present time this can only be achieved by the use of insensitive instruments in which the mechanical resonances have been removed outside the working range by increasing or diminishing the stiffness. The output is then raised by a thermionic valve amplifier suitably applied. A wide field has been found for these instruments in broadcasting, sound pictures, and gramophone reproduction.

The instrument used at the present time as a work- ing standard in most acousto-electric and electroacoustic measurements is a condenser microphone. It consists of a thin aluminium diaphragm, goldplated to prevent oxidisation, forming one plate of the condenser, the other being a circular insulated brass electrode. This is grooved, and is fixed at a small distance away from the other plate. The space between them is practically sealed, and so adds 'stiffness' to the diaphragm. Due to this, the frequency of natural resonance is effectively suppressed.

The microphone is polarised by applying 200 volts across it. Its vibrations cause variations in the capacitance, and consequently it acts like a generator producing electric currents. It is calibrated by one of three methods-the thermophone method, recommended by the C.C.I., the Rayleigh dise method, or the compensator method. The results obtained by these methods have been found by the Post Office to agree satisfactorily.

By means of an automatic device the life test of a carbon microphone can be reduced to about onefiftieth of the normal time taken. A current is first switched on--this represents the lifting of the receiver from the switch hook. A klaxon is next operated momentarily-this simulates the removal of the receiver by the subscriber; 7.5 seconds later the microphone is subjected to a rhythmic 'howl-warble" tone for 7.5 seconds, and this tone is repeated seven times at intervals of 7.5 seconds. At the end of $1 \frac{1}{2}$ minutes the klaxon is momentarily operated and the current switched off. There is then an interval of 1.5 minutes and the cycle begins again. In a week's time the wear on the telephone is the same as that made by a subscriber who in a year makes a thousand calls.

\section{South Sandwich Islands *}

r [HE first of the two Discovery Reports before us is the list of stations 137 to 433 made by R.R.S. William Scoresby in the seas between South Georgia, the Falkland Islands, and the South Shetlands from January 1928 to May 1929, and other stations made

* Discovery Reports. Issued by the Discovery Committee, Colonial Office, London, on behalf of the Government of the Dependencies of the Falkland Islands. Vol. 3. Station List, 1927-1929. Pp. $132+10$ plates. 14s. 6d. net, The South Sandwich Islands. By Dr. Stanley Kemp and A. L. Nelson; with a Report on Rock Specimens, by Dr. G. W. Tyrrell. Pp. 133-198+plates 11-31. 18s. net. (Cambridge At the University Press, 1931.)

No. 3263, VoL. 129] by members of the Discovery investigations staff from whale factory ships about the South Sandwich Islands and in the Ross Sea. This follows the first station list published in an earlier volume of the Discovery Reports.

The second report under notice deals with the South Sandwich Islands. These islands were discovered by Cook in 1775 and Bellingshausen in 1819, but they lie in stormy and frequently ice-invested seas off the track of most antarctic expeditions, and have been rarely visited except by sealers and whalers until the Discovery spent twenty days among the group in 
February and March 1930. The eleven islands, extending in a chain of 193 miles, are all small and volcanic. The largest has a circumference of only twenty-four miles. Landing is always difficult and on some islands perhaps impossible. Sulphurous fumes in places are a menace. The Discovery found no active volcanic eruptions, though five islands were emitting vapours and fumes. There were indications that volcanic activity is abating, and three islands show no recent signs of it. The rocks collected were all typical Andean lavas, as described by Dr. Tyrrell, and confirm Suess's theory of a South Antillean arc. The conspicuous ' deep' to the east, sinking to 4421 fathoms, is another noteworthy feature. The only possibility of sedimentary rocks in the whole group appears to be in Freezeland Peak on Bristol Island, but no landing was achieved there. Some of the islands have ice-caps : others have foreland glaciers. Vegetation seems to be confined to a few lichens and algæ. No flowering plants were seen. Fur seals were not found, though they probably occurred in the past. The volume contains maps and photographs of all the islands, and also an Admiralty chart of the group. It is a fairly complete monograph on the islands.

R. N. R. B.

\section{University and Educational Intelligence}

CAMBRIDGE.-An election to an Isaac Newton Studentship will be held early in the Michaelmas Term, 1932. These studentships are for the furtherance of advanced study and research in astronomy and physical optics. Members of the University are eligible who have obtained a degree in the University and were under the age of twenty-five years on Jan. 1, 1932 : failing such a candidate, a research student, subject to the same condition as to age, may be elected. The studentship will be of the value of $£ 250$ a year, and will be tenable for three years. Applications should be sent to the Vice-Chancellor between Oct. 7 and 13,1932 .

Candidates for the Michael Foster Studentship in physiology are requested to send their applications, with a statement of the course of research they propose to undertake, to Prof. J. Barcroft, Physiology School, before the end of June. The student receives the annual value of the fund (about $\mathfrak{f 1 0 0 \text { ). }}$

At Jesus College, Dr. W. H. Thorpe has been elected a fellow. He has been a research fellow of the Rockefeller Foundation at the University of California and a member of the research staff of the Imperial Institute of Entomology. At St. John's College, Dr. L. Rosenhead has been elected a fellow. He entered the college with an Open Strathcona Research Studentship for mathematics, and in 1930 was elected a Senior Research Student of the Royal Exhibition of 1851.

LoNDON.-Applications are invited for the Laura de Saliceto studentship for the advancement of cancer research, value $£ 150$ annually and tenable for not less than two years. Applications should reach the Academic Registrar, University of London, South Kensington, S.W.7, by July 1 at latest.

Oxford.--The proposed regulations for the new Final Honour School of Geography are now published, and will be dealt with by Congregation in due course. The stated subjects include physical and regional geography, cartography, the geography of man, and the history of geographical discovery. In addition to these, a special subject may be offered. The examination will be partly practical, and will include laboratory and field work. Candidates will be required to show sufficient knowledge of French or German and of the elements of physics and biology.
REading.--Dr. William B. Brierley, since 1918 head of the Department of Mycology in the Institute of Plant Pathology at the Rothamsted Experimental Station, has been appointed professor of agricultural botany in succession to Prof. J. Percival, who is retiring next September.

THE usual summer vacation course for teachers will be held at Bingley Training College, Yorks, on July 27-Aug. 10. Among the courses available are one on biology by Prof. R. Douglas Laurie, professor of zoology, University College, Aberystwyth, and another on the senior school, by Sir Percy Nunn, director of the University of London Institute of Education. Application should be submitted not later than June, while grants-in-aid applications must reach the Education Officer, County Hall, Wakefield, not later than May 31.

THE University of Cambridge publishes annually abstracts of dissertations approved for its $\mathrm{Ph} . \mathrm{D}$., M.Sc., and M.Litt. degrees (Cambridge: At the University Press, 1932). These summaries, each of which has been approved by the examiners or supervisor of studies, afford a convenient index to the scope of recent advanced study and research in the University. The sixty-one dissertations for the year 1930-31 are distributed among the faculties as follows: Physics and chemistry 24 , biology 11 , mathematics 8 , agriculture 4, engineering 3, archæology and anthropology 2, history 2, geography, medicine, music, moral science, economics, English, and classics one each. Thirty-eight of the candidates had previously studied in other universities, namely: Liverpool 5, Wales 4, Scottish universities 4, other universities in the British Isles 4, universities in Canada, South Africa, Australia, and New Zealand 11, in India 7, in the United States of America 2, Switzerland 1.

Commercial education in the United States is reviewed in Bulletin No. 20, 1931, of the Office of Education, Washington, being advance pages of the official Biennial Survey (1928-30) of Education in the United States. Few people have any idea of the enormous amount of time and energy devoted in the United States to commercial education and to the investigation and discussion of the principles and methods employed in this field in secondary schools and universities. More than a million young men and women are enrolled in business courses, exceeding the number in any field of vocational training, and during the past ten years there was an increase of more than three hundred per cent in such enrol. ments in colleges and universities. At this rate the schools of commerce will soon be throughout the States, as they are already in many institutions, the largest of the professional and vocational university schools. At the Congress of Universities of the British Empire, held at Edinburgh last July, the subject of commercial education figured prominently, and reference was made to the resistance of British universities to the dangers of being stampeded into endeavouring to make university education more 'practical', with the deplorable results experienced in American universities. This bulletin recounts facts which tend to discount the force of this criticism and show that we have something to learn not only from their mistakes but also from their thoroughgoing investigation of principles and methods. The bulletin contains summaries of the results of these and other investigations, and will, doubtless, be in request at the International Conference on Commercial Education to be held in London this year. It is obtainable, price 10 cents, from the Superintendent of Documents, Government Printing Office, Washington, D.C. 